\title{
TITLE:
}

\section{Fluorescent sensors reveal subcellular thermal changes.}

$\operatorname{AUTHOR}(\mathrm{S})$ :

Sakaguchi, Reiko; Kiyonaka, Shigeki; Mori, Yasuo

\section{CITATION:}

Sakaguchi, Reiko ... [et al]. Fluorescent sensors reveal subcellular thermal changes.. Current opinion in biotechnology 2014, 31: 57-64

\section{ISSUE DATE:}

2014-08-28

URL:

http://hdl.handle.net/2433/189742

\section{RIGHT:}

(C) 2014 Elsevier Ltd.; This is not the published version. Please cite only the published version.; この論文は出版社版でありません。引用の際に は出版社版をご確認ご利用ください。 


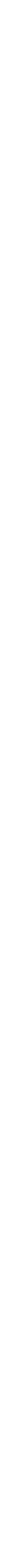




\section{HIGHLIGHTS}

Fluorescent thermosensers in live cells are reviewed.

Organic or inorganic material based sensors have higher resolution but are invasive. Genetically-encoded thermosensors are suited for organelle-specific thermosensing. Fluorescent thermonsensors are starting to unveil interesting biological phenomena. 


\section{Fluorescent Sensors Reveal Subcellular Thermal Changes}

\section{Reiko Sakaguchi ${ }^{1}$, Shigeki Kiyonaka ${ }^{2,3}$, and Yasuo Mori ${ }^{1,2,3 *}$}

${ }^{1}$ World Premier International Research Initiative-Institute for Integrated Cell-Material Sciences, Kyoto University, Kyoto 606-8501, Japan.

${ }^{2}$ Department of Synthetic Chemistry and Biological Chemistry, Graduate School of Engineering, Kyoto University, Kyoto 615-8510, Japan.

${ }^{3}$ Department of Technology and Ecology, Hall of Global Environmental Studies, Kyoto University, Kyoto 615-8510, Japan.

*To whom correspondence should be addressed.

E-mail: mori@sbchem.kyoto-u.ac.jp. 


\section{KEYWORDS}

fluorescent thermosensors; genetically encoded sensors; thermogenesis; live cell imaging

\section{ABSTRACT}

In mammals and birds, thermoregulation to conserve body temperature is vital to life. Multiple mechanisms of thermogeneration have been proposed, localized in different subcellular organelles. However, studying thermogenesis directly in intact organelles has been challenging. Visualizing patterns of thermal changes at subcellular resolution would reveal physiologically relevant spatio-temporal information, especially if this could be done in the native cellular configuration of the cell. Here we review and compare the wide variety of intracellular thermosensors currently identified. This review focuses particularly on genetically encoded sensors. It also explores the notable physiological discoveries made using these imaging methods, which are rapidly becoming indispensible to the study of thermal biology. 


\section{INTRODUCTION}

Endothermic species such as humans employ multiple strategies to maintain thermal homeostasis. They produce heat by sustaining an active metabolism and by sacrificing fuel efficiency. Some of these mechanisms increase ATP hydrolysis and are related to metabolic cycles and maintenance of the cationic gradient across membranes in liver, muscle, and brown adipocytes. Others derive heat from the proton-motive force of aerobic electron-transport via a regulated proton leak in the mitochondria of brown adipose tissue [1-3]. Obtaining data describing the patterns of thermal changes at subcellular resolution in the native cellular configuration could reveal physiologically relevant spatio-temporal information.

Earlier studies of conventional thermometers utilized infrared (IR) techniques. IR thermography is non-invasive and has reasonably good temperature resolution, but only moderate spatial resolution (up to $10 \mu \mathrm{m}$ ). Furthermore, it can only monitor the cell surface [4]. Recently, detection of heat production from a single cell was reported by a mechanical microresonator with a sensitivity of $1 \mathrm{~mW}$ [5], but these techniques are also unable to measure intracellular temperatures and inside of the cell mass. In order to observe intracellular temperature distribution, the molecular thermometers should simultaneously satisfy multiple requirements: high temperature resolution; high spatial resolution; functional independence from environmental changes in $\mathrm{pH}$, ionic strength, and surrounding biomacromolecules; and a concentration-independent output. Notably, the absence of any of these features obstructs intracellular temperature mapping [6]. Fluorescent thermosensors have attracted much attention because they allow direct measurement of intracellular temperature. They are also superior to contact thermometers in monitoring temperatures within the micro-/nanometer range because there is no interference from the medium between the probe and the evaluated object. 
Here, we will discuss the wide scope of intracellular thermometers and their features (summarized in Table 1), and explore some of the interesting physiological discoveries made using these sensors.

\section{ORGANIC AND INORGANIC MATERIAL-BASED THERMOSENSORS}

\section{Inorganic material based thermosensors}

To date, several thermal sensors based on inorganic materials have been reported. One approach uses the temperature-dependent phosphorescence intensity of the rare earth chelate Eu-TTA (europium (III) thenoyltrifluoro-acetonate) [7-11]. This thermosensitive dye was used to image intracellular heat waves evoked in Chinese hamster ovary cells after activation of the metabotropic m1-muscarinic receptor [7]. Fast application of acetylcholine onto the cells evoked a biphasic heat wave that was blocked by atropine, and after a brief delay was followed by a $\mathrm{Ca}^{2+}$ wave. Atropine alone produced a monophasic heat wave in the same cells, suggesting that its interaction with the receptor activates some intracellular metabolic pathways. This approach, however, does not have the spatial resolution to monitor subcellular events [7].

Quantum dots are another example of inorganic material-based thermosensors [12-14]. They exhibit superior brightness for detection, and are resistant to $\mathrm{pH}$ and other environmental variations that are expected to affect intracellular conditions. The spectroscopic characteristics of quantum dots have been shown to be a strong function of temperature both at the bulk and at the single-particle levels. Maestro et al. have reported the characterization of quantum dot spectral shifts dependent on intracellular temperature changes in cells under two-photon excitation [12], whereas Vetrone et al. have used Er/Yb-doped nanocrystals to look at intracellular temperature in HeLa cells [13]. More recently, a complete experiment and analysis of time-dependent localized 
intracellular temperature responses following $\mathrm{Ca}^{2+}$ stress and physical cold shock was presented, representing the first experimental evidence of non-homogeneous local temperature progression in cells [14].

\section{Synthetic polymer based thermosensors}

Synthetic polymer-based thermosensors have also been reported $[6,15,16]$. A highly hydrophilic fluorescent nanogel thermometer was maintained in the cytoplasm and emitted strong fluorescence even at high temperatures. Thus, intracellular temperature variations associated with biological processes can be monitored by this novel thermometer with a temperature resolution of better than $0.5^{\circ} \mathrm{C}$ [15].

This approach was expanded for intracellular temperature mapping, in which the authors took advantage of temperature-dependent changes in fluorescence life-time to visualize heat production from mitochondria observed as a proximal local temperature increase. The results suggest that this new synthetic polymer-based thermometry may be useful in defining the intrinsic relationship between temperature and organelle function [6].

\section{Nanodiamond thermometry}

The third approach uses coherent manipulation of the electronic spin associated with nitrogen-vacancy color centers in diamond. The technique enables the detection of small temperature variations in an ultrapure bulk diamond sample. Using nitrogen-vacancy centers in nanodiamonds, the local thermal environment on length scales as short as $200 \mathrm{~nm}$ can be measured directly. To demonstrate the feasibility of using this technique in living cells, these nanodiamonds and gold nanoparticles were introduced into WS1 cells using nanowire-assisted delivery. Temperature variation was 
measured at a single nanodiamond while slightly heating the gold nanoparticles in two different locations, without significant damage to the cells. Thus, by introducing both nanodiamonds and gold nanoparticles into a single human embryonic fibroblast, the control of temperature gradients and sub-cellular temperature mapping were demonstrated [17].

These methods have sufficient spatial resolution to make them compatible with monitoring subcellular events in single cells, but the introduction of thermosensor molecules into cells is invasive, involving microinjection or electroporation. Furthermore, there is currently no way of sub-cellular targeting of these molecules to specific organelles within the cells. Genetically encoded sensors may represent a method to overcome this problem.

\section{GENETICALLY ENCODED THERMOSENSORS}

Genetically encoded biosensors based on fluorescent proteins such as green fluorescent protein (GFP) have a number of features that make them attractive as in vivo reporters [18]. In contrast to adding chemical probes exogenously, these sensors can be explicitly targeted to defined organelles in the cell either by attaching signal sequences or by fusing the sensor to a protein that localizes to a specific domain [19]. In addition, the concentration of the sensors can be regulated if the sensor genes are put under the control of an inducible promoter. Most importantly, thermosensor probes are generated using the endogenous apparatus responsible for physiological protein expression so should not disrupt cellular conditions if appropriately designed. Genetically encoded cellular or subcellular biosensors for $\mathrm{Ca}^{2+}, \mathrm{pH}$, membrane potential, redox, and enzymatic activity have been widely utilized as non-invasive sensors to assess subcellular phenomena at different levels of biological hierarchy from individual cells 
to whole organisms $[18,20]$.

Rationally designed thermosensor using coiled coil protein

We have developed genetically encoded, GFP-based thermosensors (thermosensing GFPs: tsGFPs) that enable visualization of thermogenesis in discrete organelles within living cells. The thermosensitive coiled-coil protein TlpA is an autoregulatory repressor protein in Salmonella that senses temperature changes and controls transcription repression in a temperature-dependent manner [21-23] and was used to build a tsGFP (Figure 1a). Its thermosensing capability is derived from a rapid and reversible structural transition from a parallel coiled-coil dimer to two unfolded monomers at around $37{ }^{\circ} \mathrm{C}$. The fusion protein comprised the fluorophore-forming region of GFP inserted between tandem repeats of the coiled-coil region of TlpA. The excitation peaks at $400 \mathrm{~nm}$ and $480 \mathrm{~nm}$ of GFP (emission: $510 \mathrm{~nm}$ ) represent the neutral and anionic forms of the GFP chromophore [18], and the ratio of the fluorescence intensity of these peaks (ex400/ex480) depends on the protein structure of the GFP-tagged proteins [24]. A temperature elevation from $34{ }^{\circ} \mathrm{C}$ to $41{ }^{\circ} \mathrm{C}$ increases the magnitude of the $480 \mathrm{~nm}$ peak and decreases that of the $400 \mathrm{~nm}$ peak of tsGFP1, resulting in a sigmoidal change in the ex400/ex480 ratio across this temperature range. The midpoint of temperature-dependent fluorescence changes $\left(T_{\mathrm{c}}\right)$ is $37.6{ }^{\circ} \mathrm{C}$ (Figure $1 b)$.

The thermosensing capability of tsGFP was tested in live cells. Transient expression of tsGFP1 in HeLa cells produces uniform distribution throughout the cytosol and dramatic changes in the ex400/ex480 ratio were seen in the $35-40{ }^{\circ} \mathrm{C}$ temperature range when extracellular temperature was varied. Furthermore, tsGFP1 was fused to specific organelle-targeting sequences to yield tsGFP1-F, tsGFP1-ER and 
tsGFP1-mito, which are expressed in the plasma membrane, endoplasmic reticulum (ER) and mitochondria, respectively, to monitor subcellular thermal changes in these organelles [25].

\section{Thermosensing by fluorescent anisotropy of GFP}

Donner et al. reported the use of GFP in thermal nanoprobes for intracellular temperature mapping by monitoring its fluorescence polarization anisotropy (FPA). The method was tested on GFP-transfected HeLa and U-87 MG cancer cell lines in which heat was delivered by photothermal heating of gold nanorods surrounding the cells. A spatial resolution of $300 \mathrm{~nm}$ and a temperature resolution of about $0.4{ }^{\circ} \mathrm{C}$ were achieved $[26]$.

Furthermore, the same authors described intracellular temperature mapping in an in vivo model using a Caenorhabditis elegans (C. elegans) strain stably expressing the GFP marker in GABAergic neurons. This method clearly support two important advantages of genetically encoded probes: first, it permits established "insertion" of a probe such that it does not affect cellular mechanisms and processes; secondly, GFP can be selectively expressed in the target cells of interest. The concentration of expressed GFP in these permanently transfected species does not affect FPA measurements because these are ratiometric. This also renders the FPA measurement insensitive to fluctuations in excitation laser intensity, photo bleaching, and probe migration. The technique allows small changes in temperature distribution within a single $C$. elegans neuron to be monitored [27]. However, this technique does have certain limitations. Its FPA readout signal is not always easy to capture because it requires specialized equipment with a polarizing cube and two photodiodes measuring parallel and 
perpendicular polarization. In addition, the dynamic range of the signal is often too small to produce a useful signal:noise ratio.

\section{COMPARISON OF TECHNIQUES}

Intracellular thermosensing techniques must fulfill certain requirements such as high temperature resolution, high spatial resolution, and functional independence from environmental changes in $\mathrm{pH}$ and ionic strength. Because the heat from thermo-generating organelles diffuses rapidly throughout the cell and beyond [28], it is ideal if the sensor can be targeted directly to the organelles where the heat is generated. In these points of view, each category of technique has its own unique properties, and the characteristics and advantages/disadvantages of these methods are summarized in Table 2.

Conventional IR thermography is non-invasive and causes no cellular damage but has very poor spatial resolution $(\sim 10 \mu \mathrm{m})$. In contrast, a quantum dot, synthetic polymer or nanodiamond sensor of $\sim 100 \mathrm{~nm}$ diameter can be incorporated into cells by microinjection or with the assistance of nano-wire to give spatial resolution at the diffraction limit. These sensors also possess excellent temperature resolution, with nanodiamonds able to measure intracellular fluctuations of as low as $0.05{ }^{\circ} \mathrm{C}$. Cellular delivery is, however, highly invasive, and once inside the sensor is diffusely distributed, and thus probably reports only global temperature changes. It is very challenging to target these molecules to specific organelles.

The genetically encoded sensor system overcomes the problem of invasivity by using sensors expressed through endogenous transcription/translation and targeting apparatus. The transfection of these encoding genes might be deemed invasive, but they induce expressing of the sensor proteins without any further disruption of cellular 
integrity. By fusing them to well-established organelle-targeting signals, their localization can be strictly controlled, and the resolution with which they detect physiologically relevant temperature fluctuations is high [25-27]. Further development of in vivo thermosensors will surely be centered mainly upon these genetically encoded systems.

\section{BIOLOGICAL APPLICATIONS OF THERMOSENSORS}

Thermosensors are starting to reveal thermo-dependent mechanisms underlying interesting biological phenomena. Thermogenesis in specific organelles [28-31] and thermal properties within cells have been a focus of intense research interest and controversy for decades, but their evaluation has until now been based on indirect methods [32], which has precluded direct proof-of-concept. Now, with the help of novel thermosensors, direct measurement of thermal activity within specific cellular compartment is increasingly feasible.

\section{Visualization of thermogenesis in organelles}

A major strength of the genetically encoded system is the ability to use signaling peptide sequences to achieve sub-cellular targeting (e.g. tsGFP1-mito to mitochondria). Interestingly, tsGFP1-mito showed heterogeneity with respect to the ex405/ex488 ratio under different conditions, despite the fact that the sensor was evenly expressed across the entire mitochondrial population. A subpopulation of tsGFP1-mito showed a prominent decrease in the ex405/ex488 ratio upon application of carbonyl cyanide 3-chlorophenylhydrazone (CCCP), which uncouples oxidative phosphorylation in mitochondria to facilitate proton translocation across the mitochondrial inner membrane, which generates heat $[4,33]$. When monitored simultaneously, mitochondrial 
membrane potential and ATP production showed a positive correlation. Thus, constitutive thermogenesis occurs through the respiratory chain or oxidative phosphorylation in a subpopulation of mitochondria in HeLa cells. In a different subpopulation, the ex405/ex488 ratio was decreased only slightly by the drug and exhibited profiles similar to the ratio in control cells, suggesting that the mitochondrial populations in HeLa cells are heterogeneous with respect to their thermogenic properties (Figure 2a) [25].

Thermogenesis within the nucleus was visualized by Okabe et al., who determined that the average temperature difference between the nucleus and the cytoplasm was $0.96{ }^{\circ} \mathrm{C}$ (Figures 3a and 3b) [6]. This may originate from its intense activity (e.g. DNA replication, transcription and RNA processing) and/or from its structural separation by the nuclear membrane. Strikingly, this temperature gap between the nucleus and cytoplasm was affected by the cell cycle: the nucleus was warmer (by $0.70{ }^{\circ} \mathrm{C}$ on average) in cells synchronized to the $\mathrm{G} 1$ phase, whereas there was little temperature gap in S/G2-phased cells [6].

\section{Visualization of endogenous thermogenesis}

Endothermic species produce heat by various mechanisms. One example is heat derived from the proton-motive force of aerobic electron transport in the mitochondria of brown adipose tissue. To assess mitochondrial thermogenesis directly, brown adipocytes isolated from cold-exposed rats were infected with an adenovirus encoding tsGFP1-mito. In the cells expressing tsGFP1-mito, norepinephrine, a physiological stimulator of thermogenesis in brown adipocytes, decreased the ex405/ex488 ratio, whereas DMSO (vehicle) showed no such response (Figures $2 \mathrm{~b}$ and 2c). Thus, tsGFP1-mito allowed the first direct observation of the altered endogenous 
thermogenesis process in brown adipocytes and the correlation of subcellular thermal distribution with a specific physiological response [25].

Skeletal muscle is also a major source of non-shivering thermogenesis in many birds and animals [34]. Although controversial [32], a mechanism has been proposed that relates thermogenesis to reactions involving ATP turnover by the sarco-endoplasmic reticulum $\mathrm{Ca}^{2+}$-ATPase (SERCA) [35]. Application of cyclopiazonic acid (CPA), a reversible inhibitor of SERCA, increased the ex400/ex480 ratio in differentiated, but not undifferentiated, tsGFP1-ER-expressing C2C12 myotubes. In differentiated myotubes, the expression of SERCA1, the only active subtype in fast muscles, was increased. Therefore, tsGFP1-ER can be used to directly visualize SERCA1-mediated thermogenesis in myotubes, and may help to resolve the controversy around non-shivering thermogenesis [25].

\section{CONCLUSIONS}

The methods presented here each have advantages, such as high spatial resolution, good temperature accuracy, high biological compatibility, and easy-to-detect readout. Another major advantage is non-invasive application of sensors to monitor temperature in specific organelles, and this property will be especially useful in elucidating the intimate cellular processes involved in heating at the single intact cell level. The next goal will be to quantify actual heat production and its effect on whole cell temperature fluctuations, with a view to ultimately using these sensors in vivo by expressing them in transgenic animals. Thus, tsGFPs are likely to emerge in the very near future as an indispensible experimental tool for exploring new frontiers in the field of thermal biology. 


\section{ACKNOWLEDGEMENT}

This work was supported by grants from the Ministry of Education, Culture, Sports,

Science and Technology in Japan. 
References (* of special interest, ** of outstanding interest)

1. Nicholls DG, Locke RM: Thermogenic mechanisms in brown fat. Physiol Rev 1984, 64:1-64.

2. Silva JE: Thermogenic mechanisms and their hormonal regulation. Physiol Rev 2006, 86:435-464.

3. Block BA: Thermogenesis in muscle. Annu Rev Physiol 1994, 56:535-577.

4. Paulik MA, Buckholz RG, Lancaster ME, Dallas WS, Hull-Ryde EA, Weiel JE, Lenhard JM: Development of infrared imaging to measure thermogenesis in cell culture: thermogenic effects of uncoupling protein-2, troglitazone, and $\boldsymbol{\beta}$-adrenoceptor agonists. Pharm Res 1998, 15:944-949.

5. Inomata N, Toda M, Sato M, Ishijima A, Ono T: Pico calorimeter for detection of heat produced in an individual brown fat cell. Appl Phys Lett 2012, 100:154104-154107.

6. Okabe K, Inada N, Gota C, Harada Y, Funatsu T, Uchiyama S: Intracellular temperature mapping with a fluorescent polymeric thermometer and fluorescence lifetime imaging microscopy. Nat Commun 2012, 3:705.

** In this work, the authors have developed a fluorescent synthetic polymer where the fluorescence life time can be monitored as the function of temperature. They found that the temperature of cytosol and nucleus is significantly different. This is the first report to correlate intracellular temperature to biological functions.

7. Zohar O, Ikeda M, Shinagawa H, Inoue H, Nakamura H, Elbaum D, Alkon DL, Yoshioka $\mathrm{T}$ : Thermal imaging of receptor-activated heat production in single cells. Biophys $J$ 1998, 74:82-89.

8. Zeeb V, Suzuki M, Ishiwata $S$ : A novel method of thermal activation and temperature measurement in the microscopic region around single living cells. $J$ Neurosci Methods 2004, 139:69-77.

9. Suzuki M, Tseeb V, Oyama K, Ishiwata S: Microscopic detection of thermogenesis in a single HeLa cell. Biophys $J$ 2007, 92:L46-48.

10. Oyama K, Takabayashi M, Takei Y, Arai S, Takeoka S, Ishiwata S, Suzuki M: Walking nanothermometers: spatiotemporal temperature measurement of transported acidic organelles in single living cells. Lab Chip 2012, 12:1591-1593.

11. Takei Y, Arai S, Murata A, Takabayashi M, Oyama K, Ishiwata S, Takeoka S, Suzuki M: A nanoparticle-based ratiometric and self-calibrated fluorescent thermometer for single living cells. ACS Nano 2014, 8:198-206.

* This report focuses on the use of thermo-sensitive $\operatorname{Er}(\mathrm{III})$ thenoyltrifluoroacetonate 
together with non-thermo sensitive fluorophore to realize the ratiometric detection of temperature change within the cells. Using this technique, the heterogeneous temperature increase accompanied by $\mathrm{Ca}^{2+}$ ionophore stimulation was successfully monitored.

12. Maestro LM, Rodriguez EM, Rodriguez FS, la Cruz MC, Juarranz A, Naccache R, Vetrone F, Jaque D, Capobianco JA, Sole JG: CdSe quantum dots for two-photon fluorescence thermal imaging. Nano Lett 2010, 10:5109-5115.

13. Vetrone F, Naccache R, Zamarron A, Juarranz de la Fuente A, Sanz-Rodriguez F, Martinez Maestro L, Martin Rodriguez E, Jaque D, Garcia Sole J, Capobianco JA: Temperature sensing using fluorescent nanothermometers. ACS Nano 2010, 4:3254-3258.

14. Yang JM, Yang H, Lin L: Quantum dot nano thermometers reveal heterogeneous local thermogenesis in living cells. ACS Nano 2011, 5:5067-5071.

15. Gota C, Okabe K, Funatsu T, Harada Y, Uchiyama S: Hydrophilic fluorescent nanogel thermometer for intracellular thermometry. J Am Chem Soc 2009, 131:2766-2767.

16. Tsuji T, Yoshida S, Yoshida A, Uchiyama S: Cationic fluorescent polymeric thermometers with the ability to enter yeast and mammalian cells for practical intracellular temperature measurements. Anal Chem 2013, 85:9815-9823.

17. Kucsko G, Maurer PC, Yao NY, Kubo M, Noh HJ, Lo PK, Park H, Lukin MD: Nanometre-scale thermometry in a living cell. Nature 2013, 500:54-58.

** In this report, the authors have developed a nanodiamond based thermometer with excellent temperature resolution. The nanodiamond is delivered into the cell together with gold nanoparticle to monitor the temperature increase accompanied by laser radiation to the gold nanoparticle.

18. Tsien RY: The green fluorescent protein. Annu Rev Biochem 1998, 67:509-544.

19. VanEngelenburg SB, Palmer AE: Fluorescent biosensors of protein function. Curr Opin Chem Biol 2008, 12:60-65.

20. Chudakov DM, Lukyanov S, Lukyanov KA: Fluorescent proteins as a toolkit for in vivo imaging. Trends Biotechnol 2005, 23:605-613.

21. Hurme R, Berndt KD, Normark SJ, Rhen M: A proteinaceous gene regulatory thermometer in Salmonella. Cell 1997, 90:55-64.

22. Koski P, Saarilahti H, Sukupolvi S, Taira S, Riikonen P, Osterlund K, Hurme R, Rhen M: A new $\alpha$-helical coiled coil protein encoded by the Salmonella typhimurium virulence plasmid. J Biol Chem 1992, 267:12258-12265. 
23. Hurme R, Berndt KD, Namork E, Rhen M: DNA binding exerted by a bacterial gene regulator with an extensive coiled-coil domain. J Biol Chem 1996, 271:12626-12631.

24. De Angelis DA, Miesenbock G, Zemelman BV, Rothman JE: PRIM: proximity imaging of green fluorescent protein-tagged polypeptides. Proc Natl Acad Sci USA 1998, 95:12312-12316.

25. Kiyonaka S, Kajimoto T, Sakaguchi R, Shinmi D, Omatsu-Kanbe M, Matsuura H, Imamura H, Yoshizaki T, Hamachi I, Morii T, Mori Y: Genetically encoded fluorescent thermosensors visualize subcellular thermoregulation in living cells. Nat Methods 2013, 10:1232-1238.

** This work reports the rational engineering of genetically-encoded thermosensors by fusing the thermo responsive coiled-coil and GFP. The sensors are further engineered for organelle specific targeting within the cells, revealing the thermogenesis in the mitochondria of brown adipocytes and in the ER of myotubes for the first time.

26. Donner JS, Thompson SA, Kreuzer MP, Baffou G, Quidant R: Mapping intracellular temperature using green fluorescent protein. Nano Lett 2012, 12:2107-2111.

27. Donner JS, Thompson SA, Alonso-Ortega C, Morales J, Rico LG, Santos SI, Quidant R: Imaging of plasmonic heating in a living organism. ACS Nano 2013, 7:8666-8672.

** This work monitors the temperature-dependent fluorescence anisotropy of GFP expressed in C. elegans for thermosensing. This is the first report to actually utilize the genetically-encoded thermosensor in an animal model.

28. Schroder HJ, Power GG: Engine and radiator: fetal and placental interactions for heat dissipation. Exp Physiol 1997, 82:403-414.

29. Enerback S, Jacobsson A, Simpson EM, Guerra C, Yamashita H, Harper ME, Kozak LP: Mice lacking mitochondrial uncoupling protein are cold-sensitive but not obese. Nature 1997, 387:90-94.

30. Matthias A, Ohlson KB, Fredriksson JM, Jacobsson A, Nedergaard J, Cannon B: Thermogenic responses in brown fat cells are fully UCP1-dependent. UCP2 or UCP3 do not substitute for UCP1 in adrenergically or fatty scid-induced thermogenesis. J Biol Chem 2000, 275:25073-25081.

31. Cannon B, Nedergaard J: Brown adipose tissue: function and physiological significance. Physiol Rev 2004, 84:277-359. 
32. Cannon B, Nedergaard J: Nonshivering thermogenesis and its adequate measurement in metabolic studies. $J$ Exp Biol 2011, 214:242-253.

33. Terada $\mathrm{H}$ : The interaction of highly active uncouplers with mitochondria. Biochim Biophys Acta 1981, 639:225-242.

34. Arruda AP, Ketzer LA, Nigro M, Galina A, Carvalho DP, de Meis L: Cold tolerance in hypothyroid rabbits: role of skeletal muscle mitochondria and sarcoplasmic reticulum $\mathrm{Ca}^{2+}$ ATPase isoform 1 heat production. Endocrinology 2008, 149:6262-6271.

35. Meis L, Arruda AP, Carvalho DP: Role of sarco/endoplasmic reticulum $\mathrm{Ca}^{2+}$-ATPase in thermogenesis. Biosci Rep 2005, 25:181-190.

36. Yap SV, Ranson RM, Cranton WM, Koutsogeorgis D: Decay time characteristics of $\mathrm{La}_{2} \mathrm{O}_{2} \mathrm{~S}$ : Eu and $\mathrm{La}_{2} \mathrm{O}_{2} \mathrm{~S}$ :Tb for use within an optical sensor for human skin temperature measurement. Appl Opt 2008, 47:4895-4899.

37. Hilderbrand SA, Shao F, Salthouse C, Mahmood U, Weissleder R: Upconverting luminescent nanomaterials: application to in vivo bioimaging. Chem Commun (Camb) 2009:4188-4190.

38. Shang L, Stockmar F, Azadfar N, Nienhaus GU: Intracellular thermometry by using fluorescent gold nanoclusters. Angew Chem Int Ed 2013, 52:11154-11157.

* Ultra small gold nanocluster $(<2 \mathrm{~nm}$ in diameter) that can be delivered into the cells by endocytosis is developed. Both the fluorescence lifetime and emission intensity change considerably over the physiological temperature range. This thermosensor successfully detected the temperature fluctuation in HeLa cells caused by the heat that was applied externally.

39. Chapman CF, Liu Y, Sonek GJ, Tromberg BJ: The use of exogenous fluorescent probes for temperature measurements in single living cells. Photochem Photobiol 1995, 62:416-425.

40. McCabe KM, Lacherndo EJ, Albino-Flores I, Sheehan E, Hernandez M: LacI(Ts)-regulated expression as an in situ intracellular biomolecular thermometer. Appl Environ Microbiol 2011, 77:2863-2868. 


\section{Figure Legends}

Figure 1. Design and biophysical characterization of tsGFP thermosensors. (a) Top, schematic diagram of the tsGFP thermosensors. Coiled-coil regions of TlpA are shown in gray. GFP (green) is inserted in-frame in between tandemly repeated coiled-coil regions of TlpA. Bottom, the tandem formation of the coiled-coil structure and the resulting fluorescence change of tsGFP are associated with thermal changes. Ex, excitation. (b) Left, fluorescence excitation spectra of tsGFP1 at various temperatures. Emission is monitored at $510 \mathrm{~nm}$. Right, temperature-dependent changes in the ex400/ex480 ratio of tsGFP1 and GFP $(n=3)$. The figures are reproduced from Figure 1 in ref. [25].

Figure 2. Subcellular-targeted thermosensors visualize intracellular temperature distribution. (a) Pseudocolor confocal images of ratio (ex405/ex488) in tsGFP1-mito-expressing cells before and after CCCP treatment at $37{ }^{\circ} \mathrm{C}$. Scale bars indicate $10 \mu \mathrm{m}$ (whole image) and $3 \mu \mathrm{m}$ (inset). (b) A representative confocal image and ratiometric pseudocolor image of brown adipocytes expressing tsGFP1-mito. Scale bar indicates $10 \mu \mathrm{m}$. (c) Fluorescent responses indicative of temperature rises evoked by 10 $\mu \mathrm{M}$ norepinephrine ( $\mathrm{n}=24$ or 21 cells for DMSO or norepinephrine, respectively) in tsGFP1-mito-expressing brown adipocytes at $37^{\circ} \mathrm{C}$. Left, averaged time courses. Right, $\Delta$ ratio(ex405/ex488) after NE application. The figures are reproduced from Figure 4 and Figure 5 in ref. [25].

Figure 3. Subcellular-targeted thermosensors visualize intracellular temperature distribution. (a) Confocal fluorescence image (left) and fluorescence lifetime image (right) of fluorescent polymeric thermometer. (b) Higher temperature in the nucleus. Histograms of the fluorescence lifetime in the nucleus and in the cytoplasm in a representative cell (the leftmost cell in a). The s.e. in determining a temperature was $0.38{ }^{\circ} \mathrm{C}$. The figures are reproduced with permission from panel a and $\mathrm{b}$ of Figure 4 in ref.[6]. 
a

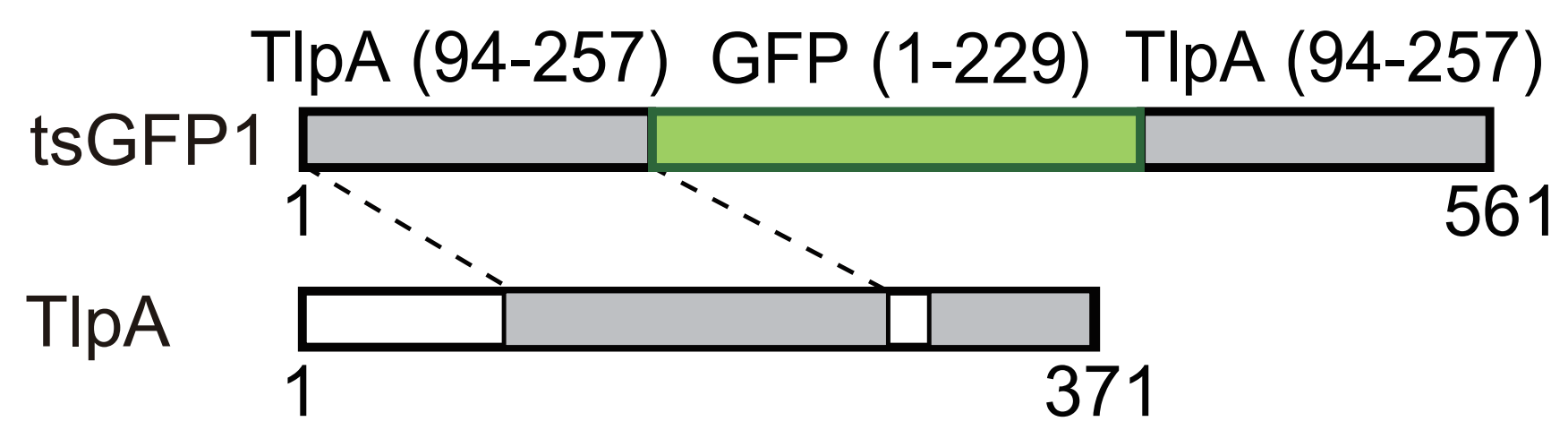

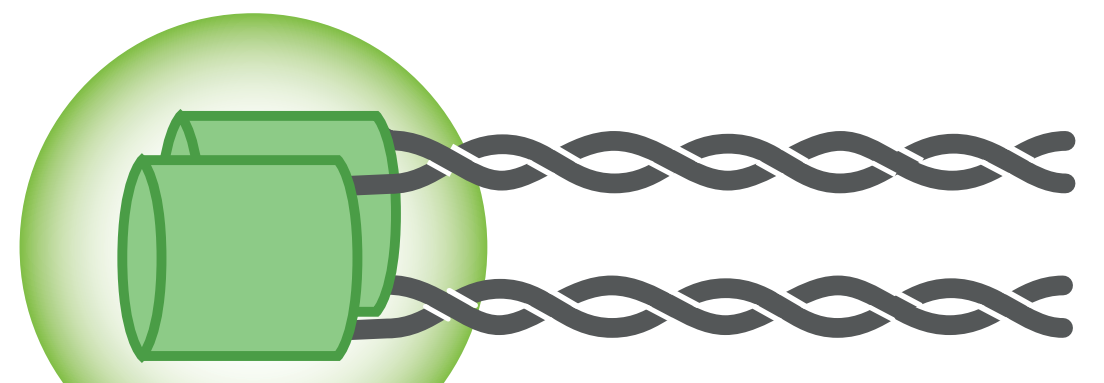

ex $400 \mathrm{~nm}$

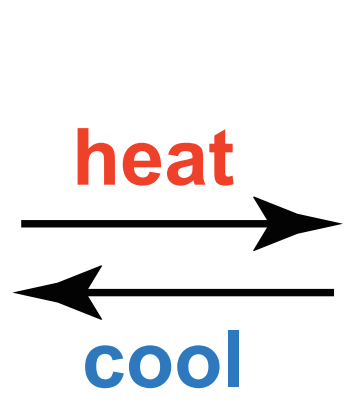

cool

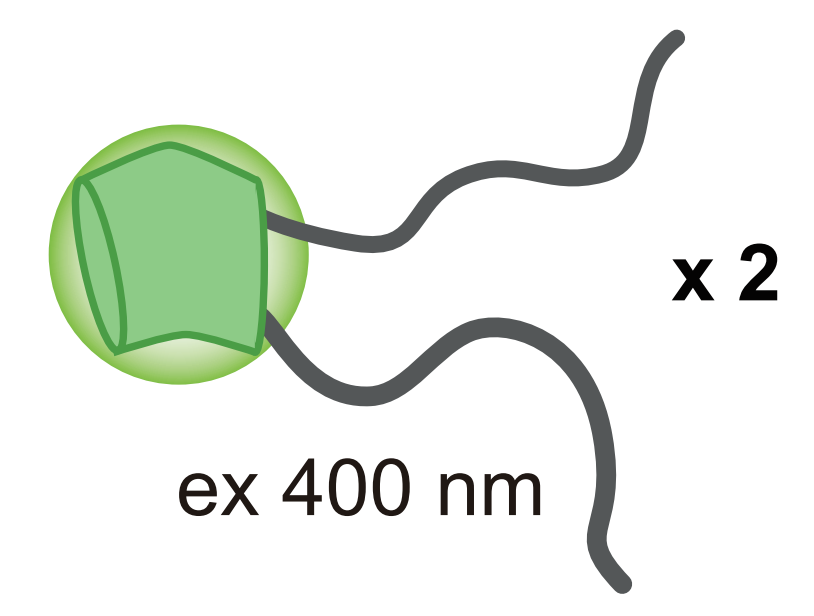

b
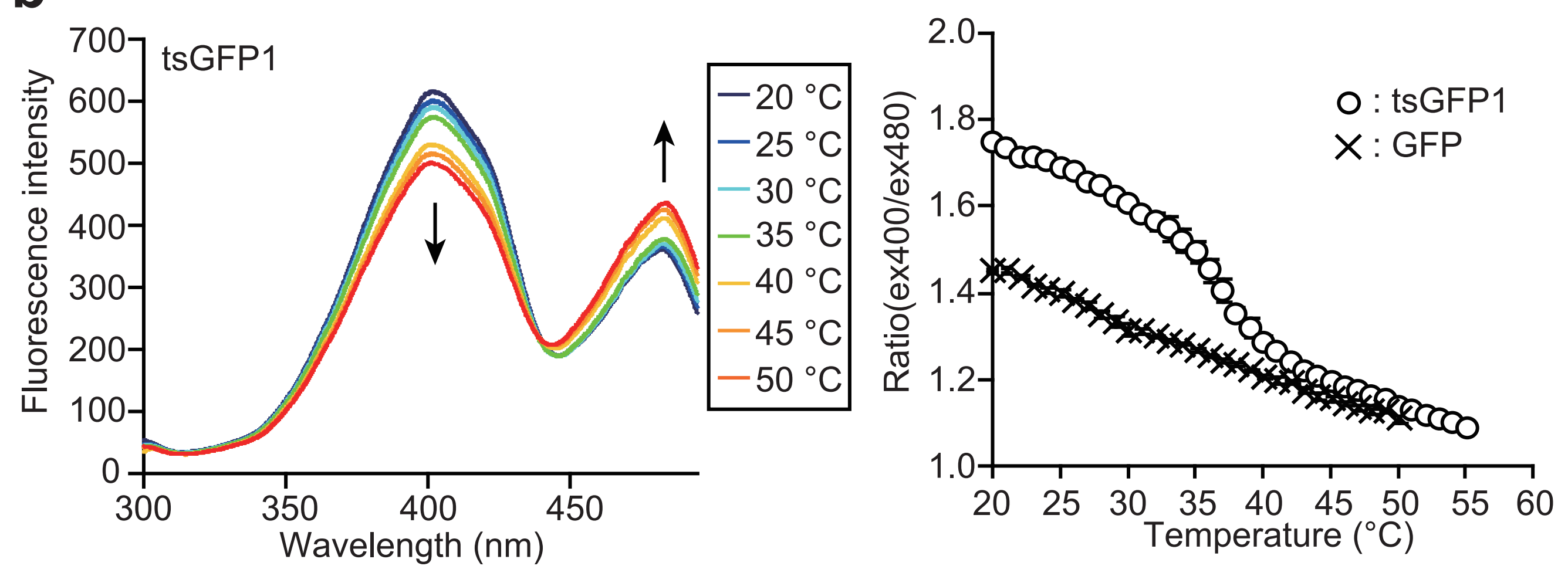

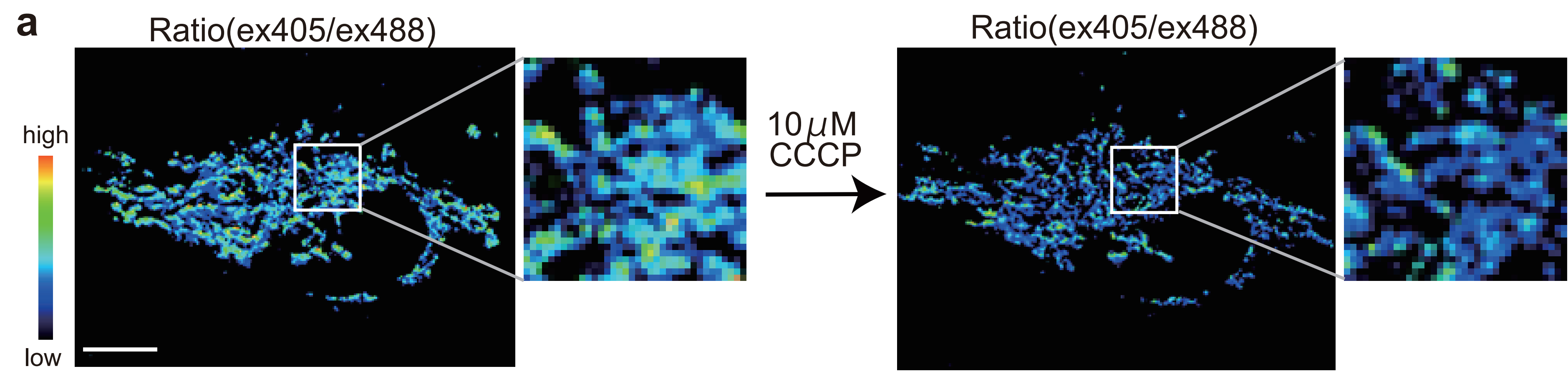

b
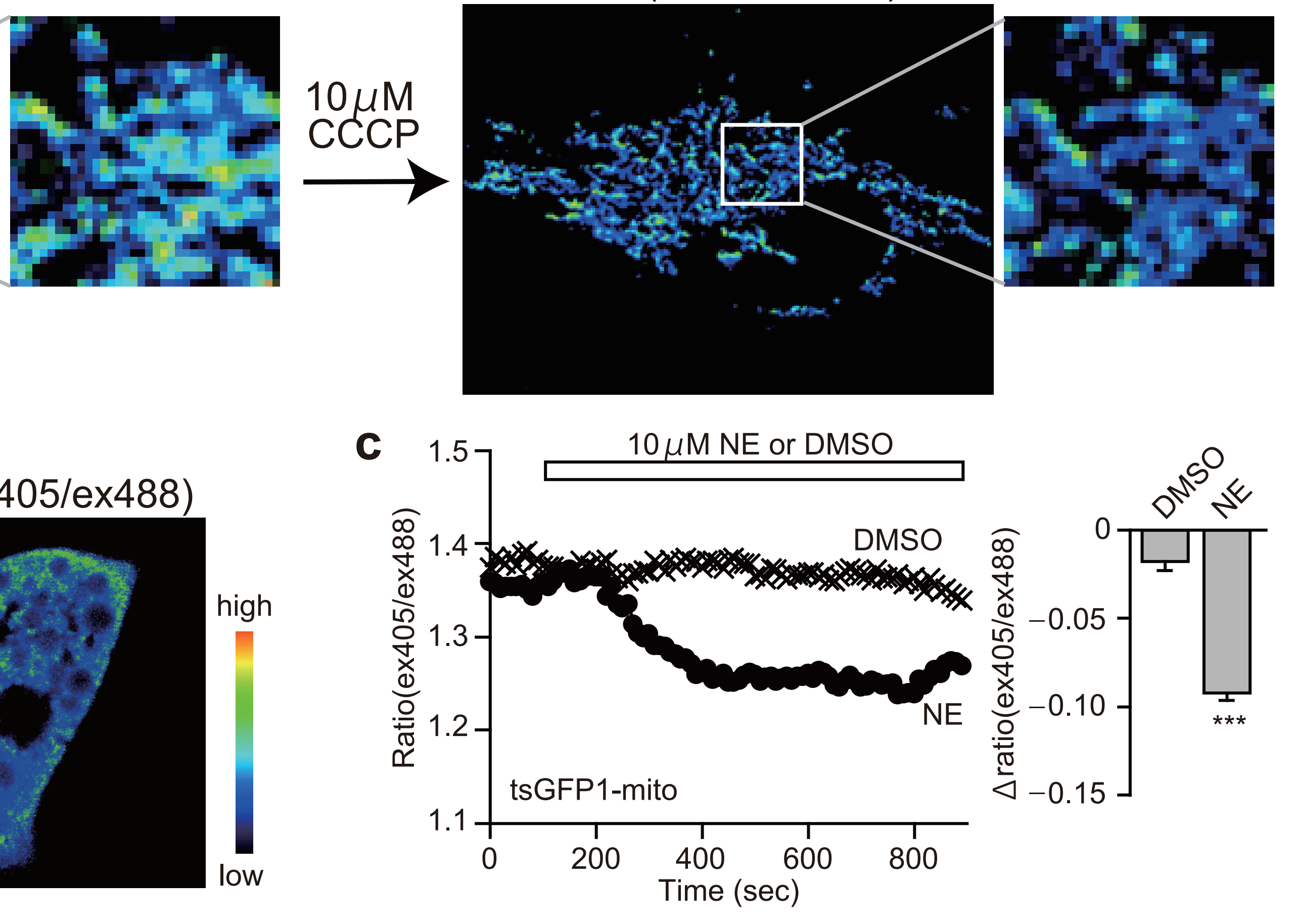

Ratio(ex405/ex488)

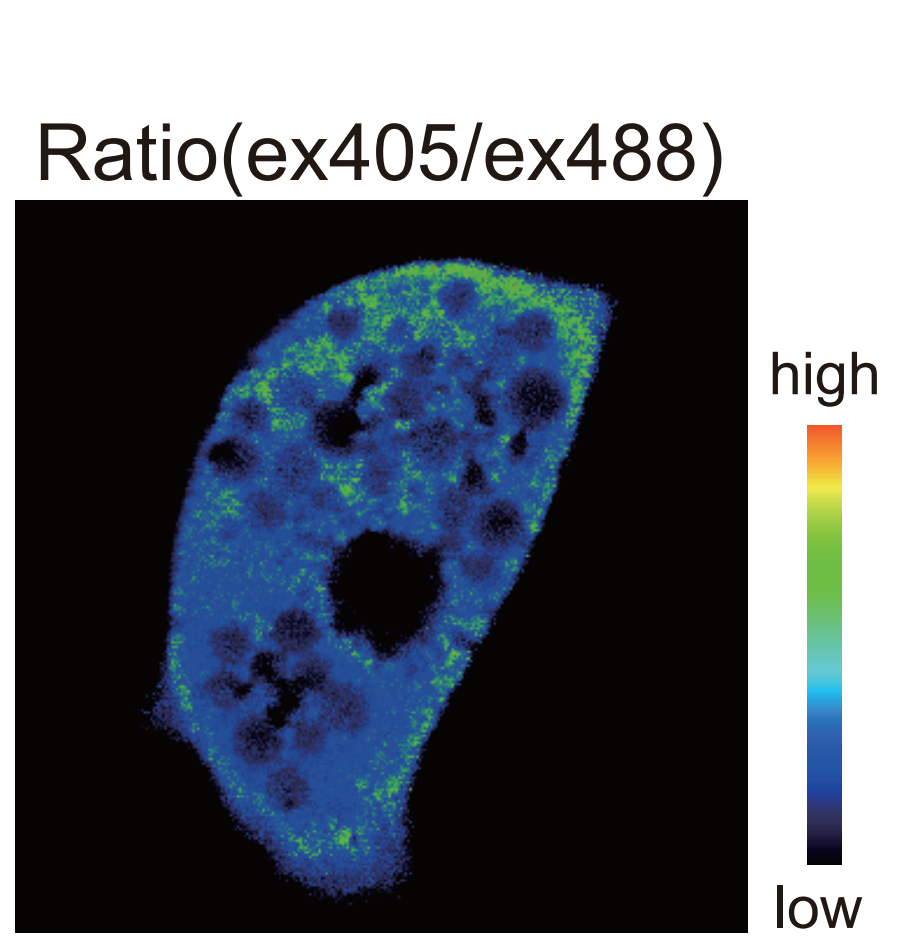




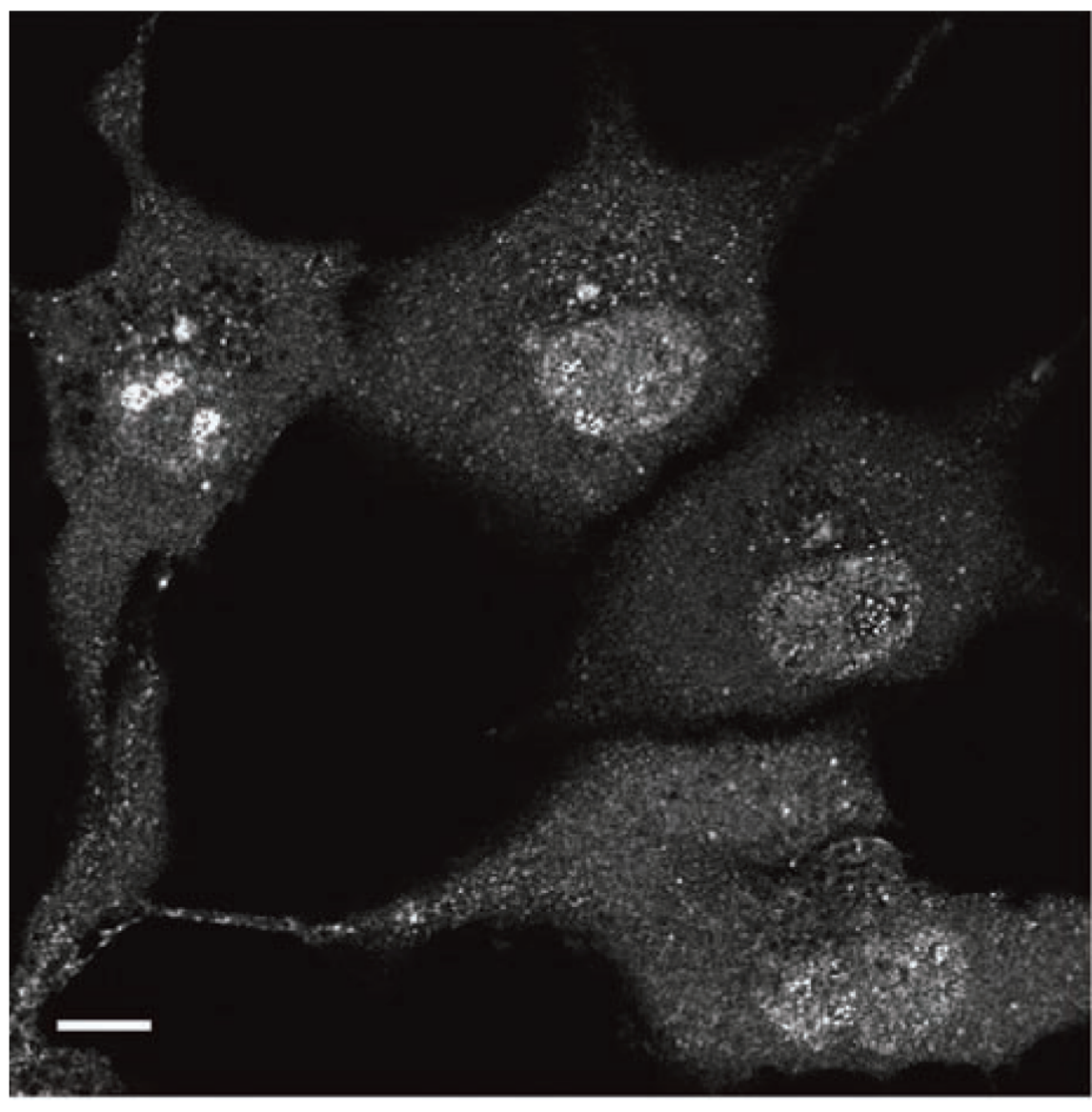

$4.6\left(28^{\circ} \mathrm{C}\right)$

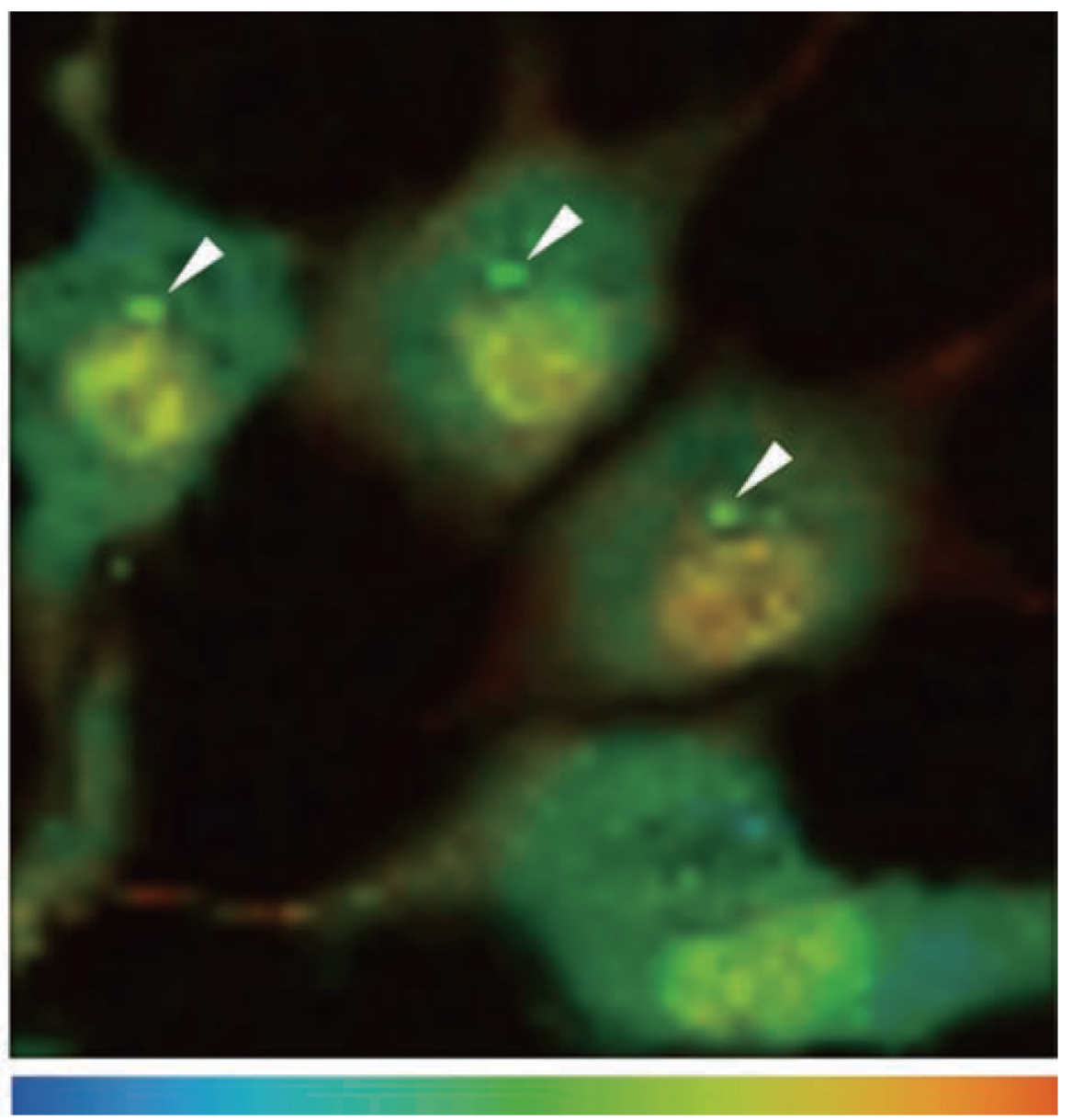

$7.6\left(40^{\circ} \mathrm{C}\right)$

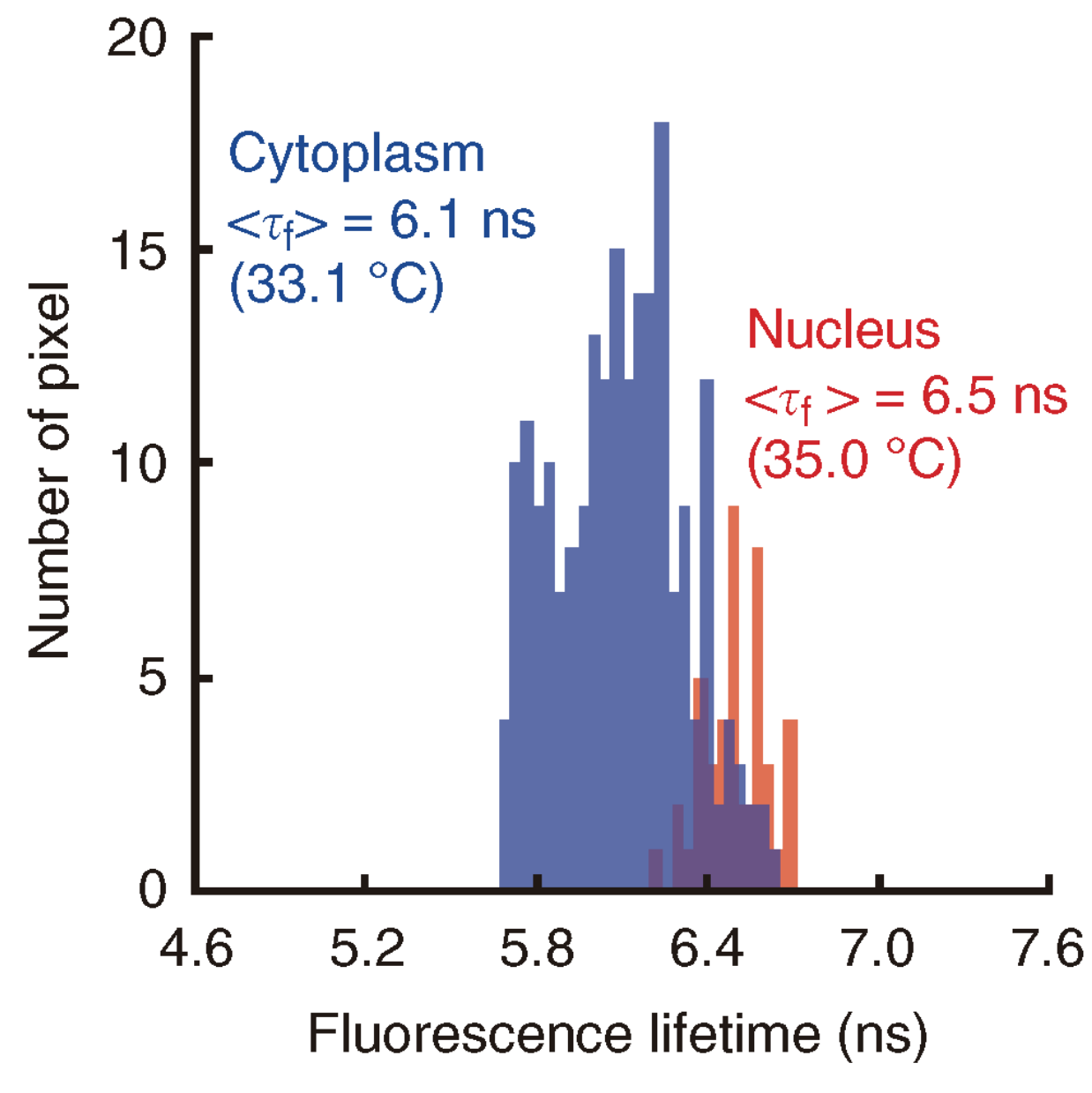

Fluorescence lifetime (ns) 
Table 1 Reported thermosensing techniques for single cells

\begin{tabular}{|c|c|c|c|c|c|}
\hline Year & Last author & Read out mode & Material & Category & Ref \\
\hline 1998 & Yoshioka & Phosphorescence intensity & Eu-TTA & Inorganic & [7] \\
\hline 2004 & Ishiwata & Phosphorescence intensity & Eu-TTA & Inorganic & [8] \\
\hline 2007 & Ishiwata & Fluorescence intensity & Eu-TTA & Inorganic & [9] \\
\hline 2012 & Suzuki & Fluorescence intensity & Eu-TTA & Inorganic & [10] \\
\hline 2014 & Suzuki & Fluorescence ratio & Eu-TTA & Inorganic & [11] \\
\hline 2010 & Capobianco & Fluorescence intensity & $\mathrm{Er}^{3+}$ & Inorganic & [13] \\
\hline 2010 & García Solé & Fluorescence intensity & Quantum dot & Inorganic & [12] \\
\hline 2011 & Lin & Fluorescence spectrum & Quantum dot & Inorganic & [14] \\
\hline 2013 & Lukin & Fluorescence intensity & Nanodiamond & Inorganic & [17] \\
\hline 2008 & Koutsogeorgis & Fluorescence decay rate & $\begin{array}{l}\mathrm{La}_{2} \mathrm{O}_{2} \mathrm{~S}: \mathrm{Eu} \text { and } \\
\mathrm{La}_{2} \mathrm{O}_{2} \mathrm{~S}: \mathrm{Tb}\end{array}$ & Inorganic & [36] \\
\hline 2009 & Weissleder & Luminescence & $\begin{array}{l}\mathrm{Y}_{2} \mathrm{O}_{3} \\
\text { nanoparticles }\end{array}$ & Inorganic & [37] \\
\hline 2013 & Nienhaus & Fluorescence intensity & Gold particle & Inorganic & [38] \\
\hline 1995 & Tromberg & Fluorescence decay time & NBD, laurdan & Organic & [39] \\
\hline 2009 & Uchiyama & Fluorescence intensity & $\begin{array}{l}\text { Synthetic } \\
\text { polymer }\end{array}$ & Organic & [15] \\
\hline 2012 & Uchiyama & Fluorescence life time & $\begin{array}{l}\text { Synthetic } \\
\text { polymer }\end{array}$ & Organic & [6] \\
\hline 2013 & Uchiyama & Fluorescence life time & $\begin{array}{l}\text { Synthetic } \\
\text { polymer }\end{array}$ & Organic & [16] \\
\hline 2011 & Hernandez & Fluorescence intensity & $\begin{array}{l}\beta \text {-galactosidase } \\
\text { activity }\end{array}$ & $\begin{array}{l}\text { Genetically- } \\
\text { encoded }\end{array}$ & [40] \\
\hline 2012 & Quidant & Fluorescence anisotropy & WT GFP & $\begin{array}{l}\text { Genetically- } \\
\text { encoded }\end{array}$ & [26] \\
\hline 2013 & Quidant & Fluorescence anisotropy & WT GFP & $\begin{array}{l}\text { Genetically- } \\
\text { encoded }\end{array}$ & [27] \\
\hline 2013 & Mori & Fluorescence ratio & $\begin{array}{l}\text { Engineered } \\
\text { GFP }\end{array}$ & $\begin{array}{l}\text { Genetically- } \\
\text { encoded }\end{array}$ & [25] \\
\hline
\end{tabular}


Table 2 Properties of thermosensing techniques for live cells

\begin{tabular}{lcccccc}
\hline Category & $\begin{array}{c}\text { Spatial } \\
\text { resolution }\end{array}$ & $\begin{array}{c}\text { Temperature } \\
\text { resolution }\end{array}$ & $\begin{array}{c}\text { Intracellular } \\
\text { imaging }\end{array}$ & $\begin{array}{c}\text { Organelle } \\
\text { targeting }\end{array}$ & $\begin{array}{c}\text { Non- } \\
\text { invasive }\end{array}$ & $\begin{array}{c}\text { In vivo } \\
\text { application }\end{array}$ \\
\hline Infra-red & - & + & - & - & ++ & $+/-$ \\
Inorganic & ++ & ++ & + & $+/-$ & - & - \\
Organic & ++ & ++ & + & $+/-$ & - & - \\
Genetically- & ++ & + & ++ & ++ & ++ & ++ \\
encoded & + & & & & ++ excellent, $+:$ good, + /-: fair, $-:$ poor
\end{tabular}

